\title{
QUALITY FUNCTION DEPLOYMENT (QFD) AND THE ANALYTIC NETWORK PROCESS (ANP)
}

\author{
Fariborz Y. Partovi \\ Drexel University
}

\begin{abstract}
The purpose of this paper is to show how the Analytic Network Process (ANP) can be integrated with Quality Function Deployment (QFD) to facilitate product and process decisions in manufacturing and service organizations.

The use of ANP/QFD is an effective way to deal with decisions that involve competitive analysis. We will show examples of ANP/QFD framework in new product and service design decisions, location decision, process choice decision, and technology planning and justification decisions. In addition suggestions for other areas of research will be discussed
\end{abstract}

Keywords: ANP, QFD 